\title{
FLATTENING HIERARCHIES. SLI AS A WINDOW ONTO THE ARCHITECTURE OF LANGUAGE*
}

\author{
Guillermo Lorenzo (iD) \& Elena Vares (D)
}

\begin{abstract}
Children with SLI have traditionally been diagnosed as exhibiting core deficits affecting their phonological and morphological performance. These well-known aspects of SLI, at least, thus appear to refer the syndrome to the Externalization component of the Faculty of Language. If such a conclusion is on the right track, then it could be predicted that Linearization, also an aspect of Externalization according to the Minimalist architecture of the Faculty of Language, should also be a typical locus of affectation in cases of SLI. This paper presents and interprets data regarding comprehension and production phenomena of a population of Spanish-speaking children with SLI. These data support the aforementioned prediction, thus reinforcing the design specifications that the Minimalist Program attributes to language capacity.
\end{abstract}

\section{Introduction}

The aims of this paper are twofold. Firstly, to furnish data obtained in experiments conducted with Spanish-speaking children with Specific Language Impairment (SLI) and, through these data, to contribute to a better understanding of SLI as a general phenomenon (cf. Bishop 1997, Leonard 2014, Stavrakaki 2015). Secondly, to provide a coherent, unified explanation for that data. If our ideas are on the right track, this explanation will also serve to offer empirical support to the architecture of the language faculty as envisioned within recent developments of the Minimalist Program (namely, Chomsky 2013, 2016).

SLI is a cover term for different deficits related to speech and language that putatively affect every linguistic level of analysis, yet not always coincidentally in a single individual, but rather showing different degrees of affectation in each particular case (van der Lely 2005). One popular classification of SLI-associated deficits, elaborated in the pregenomic era of the comprehension of the syndrome, but which still remains popular and captures its manifold manifestations (Rapin \& Allen 1983, Rapin \& Allen 1987), teases apart cases that relate to central linguistic processes (roughly, syntax/semantics/pragmatics) and

\footnotetext{
*This paper has benefitted from a grant of the Spanish Government (FEDER/Ministerio de Ciencia, Información y Universidades - Agencia Estatal de Investigación) (Ref. FFI2017-87699P). We are grateful to three anonymous reviewers for their helpful comments. All remaining errors are our own.
} 
cases that relate to expression (roughly, phonetics and phonology, but also the phonology/syntax interface). Curiously enough, such a general distinction matches rather well with Chomsky's current strong distinction between a thought-related component of the language faculty, which comprises core syntax, and an ancillary component devoted to exteriorization, which comprises morphology, phonology and phonetics (Chomsky 2013, 2016). In this paper, we shall specifically deal with aspects of SLI which, according to this theoretical framing, relate to expression.

Following Rapin and Allen's characterization, expressive aspects of SLI range from cases of verbal dyspraxia, in which articulation can be affected to the point of mutism, to the (sometimes overlapping) situation of auditory agnosia, in which speech is hardly perceived as such. In between, a 'phonologic programming deficit' is identified, along with mixed deficits, in which problems of comprehension are observed which suggest an affectation in the phonology/syntax interface (cf. Reilly et al. 2014, Bishop 2014). ${ }^{1}$

According to the suggested view, the difficulties typically observed in populations with SLI in dealing with morphological processes are also to be incorporated within this expressive side of the condition. Lasting problems with verb inflection and the tendency to use uninflected or default forms (such as infinitives or third persons, depending on the language), which reflect difficulties in dealing with the underlying paradigms, are phenomena extensively documented in the literature (Gopnik 1990, Gopnik \& Crago 1991). Developmentally speaking, illtimed stages has been observed as being a distinctive seal of SLI: e.g. the stage at which children freely alternate the use of infinitives and properly inflected verbs, firstly attested in English and subsequently in other language typologies (Rice \& Wexler 1996a, 1996b, Rice et al. 1995, Wexler 1994, for English; Grinstead et al. 2014, for Spanish), or the stage at which children freely omit object clitics in Romance languages (Tuller et al. 2011, Gavarró 2012).

Within this context, the suspicion arises that at least the expression dimension in Rapin and Allen's $(1983,1987)$ classification of SLI deficits may constitute a coherent natural class of syndromes, which affects the exteriorization channel of language. The idea is not new, but has been suggested and empirically supported with data from Afrikaans in Corver et al. (2012). According to this view, the locus of SLI must be placed at the syntax-phonology interface, starting at the spell-out point, where

\footnotetext{
${ }^{1}$ Rapin and Allen's distinctions were originally elaborated for populations of preschool children. In any event, an inspection of more recent literature, covering a wider range of ages (e.g. Verhoven \& van Balkon 2004), reveals a picture largely congenial with that of Rapin and Allen, in terms of the variegated forms of affectation.
} 
chunks of abstract expressions are transferred to exteriorization. The following quote nicely synthesizes the idea:

Based on our data, we conclude that the language problem of children with SLI appears to lie neither in the mapping from lexicon to syntax (thus in the selection of a lexical item as a member of the numeration) nor in the computational system, but in the mapping of an adult-like syntactic representation onto a proper sound representation. (Corver et al. 2012:71)

Our contribution to this viewpoint will be specifically focused on the following associated issue. Taking into account that difficulties related to Morphology, Phonology, and Phonetics have been extensively documented in speakers with SLI, it appears to be relevant to verify whether difficulties are also attested that relate to the 'flattening' operation of the syntactic hierarchies for the linearization of units in speech, an operation that current Minimalism locate at the very onset of the Externalization module (Chomsky 1995 and subsequent works). In this paper, the production and comprehension of wh-questions by children with SLI will be used as the litmus test for the hypothesis that the transfer from hierarchical to linear order, plausibly the first step in the way to exteriorization, is also affected. Wh-questions have previously been pinpointed as reflecting typically SLI-associated difficulties in core syntax, mostly (but not always) movement (e.g. Leonard 1995, van der Lely 1998, de Villiers et al. 2001, for English; Stavrakaki 2006, for Greek; Hamann 2006, Jakubowitz 2011, for French; Friedmann \& Novogrodsky 2007, for Hebrew; Håkansson 1998, Hansson \& Nettelbladt 2006, for Swedish, etc.). Alternatively, Ullman \& Pierpont (2005) and Hsu \& Bishop (2014) have pointed to linearization/sequencing as a possible explanation. In this paper we shall support this latter view, although from a partially diverging perspective, according to which the difficulties which are here of interest are to be located at the very onset of the exteriorization channel.

The paper is organized in two main sections. Section 2 introduces the independently motivated model of language within which our proposals are framed, namely the Minimalist architecture of the language faculty, as recently qualified by Chomsky and coworkers. After this, Section 3 introduces the data (and interpretation thereof) from which we derive our conclusion that linearization is indeed a prominent locus of SLI affectation. Some concluding remarks close the paper.

\section{The Minimalist Program and the dual nature of FL}

Chomsky has lately endorsed a strong divide within the Faculty of Language (FL) between a part corresponding to an internal Language of Thought (LoT), and a part corresponding to an Externalization channel (Ext) (cf. Chomsky 2016). LoT is, according to this view, a combinatorial 
system that is fed by word-like units, the atoms of computation. ${ }^{2}$ These atoms are almost like words, but devoid of an associated phonological matrix (Chomsky 2016:41). The system outputs articulated abstract expressions, which are subserved to other language-associated systems for assessing complex conceptualization tasks and intentional behavior. According to Chomsky, LoT functions on the basis of the recursive binary set-formation operation Merge, apt to create expressions of an indeterminate length (Chomsky 1995:226). Merge may work both as (1) E-Merge, that accesses the atoms of computation from the Lexicon - not to be confused with the language-particular Vocabulary, and as (2) IMerge, that accesses previously constructed sets (Chomsky 2004). An independent operation, Labelling, breaks the symmetry within the sets and creates hierarchies (Chomsky 2013).

Words proper, or vocabulary items, belong to Ext, namely to a stage of externalization (Wording or Morphology) at which the atoms of computation of an abstract expression are put into correspondence with items of the corresponding language-particular Vocabulary (Chomsky 1995:Ch. 4). Vocabulary items have, among other features, an associated phonological form, so after wording and subsequent phonological arrangements, the expression reaches a stage where it can instruct the language-associated sensory-motor systems.

The (two-dimensional) hierarchies created by Labelling, obviously relevant to conceptual-intentional interpretation, are then flattened for externalization (Chomsky 1995:334-340), given the one-dimensional character of speech (Tesnière 1959). This stage is crucial, since it gives rise, on the one hand, to the distinguishing seals of the abstract expressions pertaining to thought, and on the other, to the material expressions that make them apt for communication, paving the way for the dual nature of language, according to Chomsky's view: (a) Language as the means for providing "an unbounded array of hierarchically structured expressions" (Chomsky 2016:4), relevant to complex thought - LoT; and (b) language as a realm for "order and other arrangements" - Ext, relevant to contextual accommodation and other pragmatic effects (Chomsky 2013:36). According to the widely extended minimalist metaphysics, the distinction is a far-reaching one, as Table 1 tries to capture.

As for the flattening function in charge of compressing hierarchically structured internal expressions for externalization, it has generally been assumed, since the pioneering work of Kayne (1994), that it operates on the basis of an algorithm (Linear Correspondence Axiom; LCA) that takes advantage of a prominent structural property (command) in order to convert hierarchies into linear order. According to this algorithm, a unit

\footnotetext{
${ }^{2}$ Chomsky's LoT is not exactly Fodor's $(1975,2008)$ LOT. For the purposes of this paper, suffice it to say that, for Fodor, LOT is language-independent and Language is basically Chomsky's Ext (Fodor 1983).
} 
Table 1. A synthesis of the 'LoT vs. Ext' divide (Berwick \& Chomsky 2011, Berwick \& Chomsky 2016, Chomsky 2001, Chomsky 2005, Chomsky 2010)

\begin{tabular}{ll}
\hline LoT & Ext \\
\hline - uniform & locus of language-particular \\
- perfect & variation \\
- innovative, recent trait of & source of linguistic \\
the human mind & imperfections \\
fully naturally evolved & old trait with many \\
trait & homologues in the animal mind \\
& $\begin{array}{l}\text { incorporates manifestations } \\
\text { of cultural evolution }\end{array}$ \\
\hline
\end{tabular}

takes precedence over the ones that it asymmetrically commands after Labelling - roughly speaking, those contained within the (sub)expression with which the former has merged (Epstein et al. 1998; cf. Zwart 2011). It is also generally accepted that, as originally suggested in Uriagereka (1999), abstract hierarchical expressions are chunked and successively transferred to Ext on a cyclic, bottom-up basis. It is now also widely accepted (but on different grounds) that the main structural milestones (Phases) for such iterative transfer of material to Ext are the $v \mathrm{P}$ and $\mathrm{CP}$ structural levels, the former corresponding with the expression of a complete predicateargument structure, and the latter with a full-fledged proposition with tense and illocutionary force (Boeckx 2014, Chomsky 2000; cf. Citko 2014). A final qualification is maybe in order. The language architecture thus far commented on is directly conceived of as a model of "competence". It therefore only relates to "performance" indirectly, as in Chomsky (1965), in the sense that the speaker/hearer needs to access that internalized knowledge during real-time processing. This also entails, among other things, that we shall be using "flattening" as generically referring to flattening proper (in production) and to unflattening (in comprehension).

In this expedient presentation, we above all want to stress the radical differentiation between an internal computational core, on the one hand, and a peripheral externalization channel, on the other, which is one of the most distinctive hallmarks of current Minimalist theorizing. Figure 1 tries to capture this. The bottom line is that Ext comprises a series of stages (Linearization, Morphology, Phonology, Phonetics) that successively gear up bi-dimensional (hierarchical) thought-related expressions for their communication as a one-dimensional (flat) sequence of physically realized units. From this point of view, which for the sake of this paper we shall take as essentially correct, the above-mentioned stages (Linearization, Morphology, Phonology, Phonetics) compound a self-contained module, the operations of which can be said to belong to a 


\section{Guillermo Lorenzo \& Elena Vares}

common natural class of devices, different from the core computational module. Thus, the most likely expectation is that difficulties relating to all these stages tend to accumulate in a single individual, while compounding different patterns of affectation from one individual to another. ${ }^{3}$

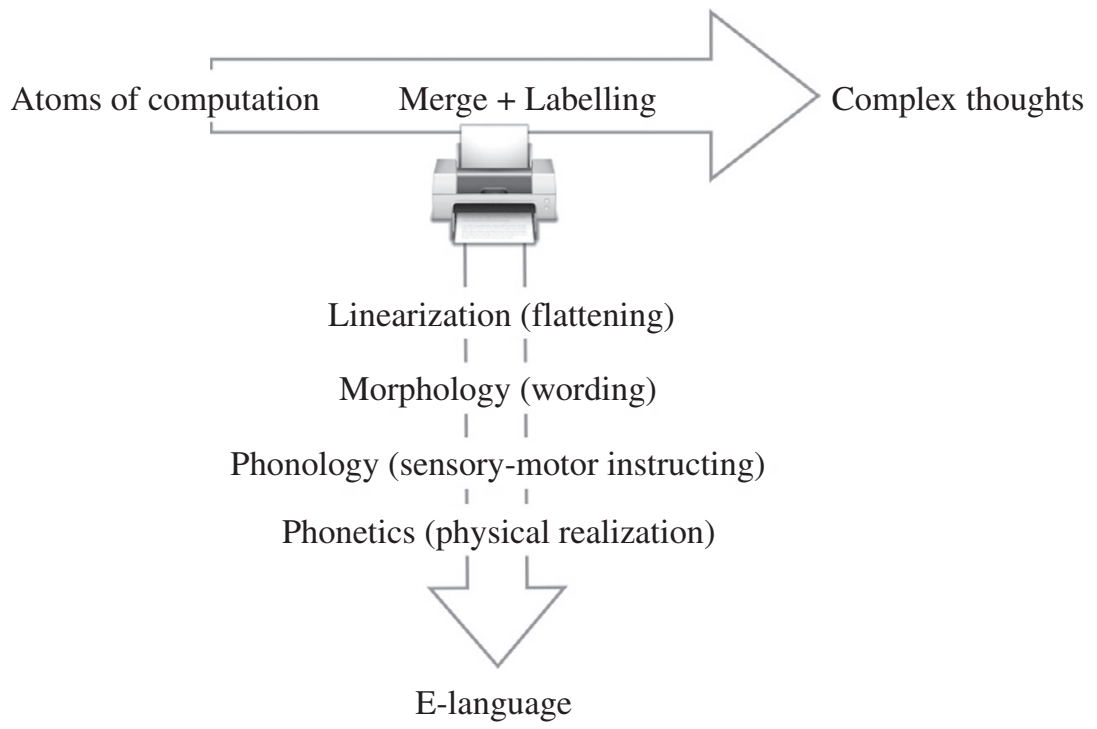

Figure 1. The Faculty of Language (in a broad sense) according to current minimalist thought. The figure echoes Berwick \& Chomsky's (2011) metaphor of considering Ext as a printer-like peripheral device associated to language proper (LoT).

\section{Impaired linearization: some evidence}

We base this section on data obtained in different experimental sessions aimed at observing the performance with wh-questions of a population of Spanish-speaking children with SLI, both in comprehension (3.1) and production (3.2) tasks.

\subsection{Linearization as a barrier for comprehension}

We chose wh-questions as a putative locus of linearization (or "flattening") problems inspired by previous literature that points to different

\footnotetext{
${ }^{3}$ In this particular aspect, we slightly part ways with Corver et al.'s (2012) otherwise congenial approach, since, in their opinion, word mislinearizations in children with SLI, which they consider minor and few, have nothing to do with hierarchical organization (Corver et al. 2012:84-86) - see below. As the rest of our paper tries to show, we, in contrast, believe that the hierarchy-order transfer, a critical point in the minimalist architecture of FL, also shows itself as a critical point for SLI-associated impairments.
} 
kinds of serial order-related difficulties affecting children with SLI in this domain. These difficulties have been explained in different ways (see below), but always relating them to core syntax, rather than to externalization. More precisely, we decided to test, on the one hand, difficulties with understanding wh-questions with an object Wh-Phrase (WhP) - see (2) below - as opposed to wh-questions where the WhP is the subject - see (1) below; and, on the other hand, with understanding whquestions in which the object $\mathrm{WhP}$ is of the $\mathrm{Wh}+\mathrm{NP}$ type (i.e. a qué chico; to which boy; 'which boy'; see $2 \mathrm{~b}$ below), as opposed to cases in which the WhP consists of only a Wh-word (i.e. a quién; to whom; 'who'; see (2a) below):

(1) Subject Wh-Phrase

a. ¿Quién está haciendo cosquillas a la chica?

Who is making tickles to the girl

'Who is tickling the girl?'

b. ¿Qué chica está calzando al chico?

What girl is putting-shoes to-the boy

'Which girl is putting the boy's shoes on?'

(2) Object Wh-Phrase

a. ¿A quién está empujando la chica?

To who is pushing the girl

'Who is the girl pushing?'

b. ¿A qué chico está fotografiando la chica?

To what boy is taking-a-picture the girl

'Which boy is the girl taking a picture of?'

\subsubsection{Experiment 1: Participants, materials and results}

We tested 22 Spanish-speaking children with SLI (7 girls, 15 boys), ranging from $5 ; 1$ to $15 ; 0$ (M: 10;4), and 22 Spanish-speaking children with typical development (matched for gender and age). ${ }^{4}$ Participants with SLI had an official diagnosis and had passed tests confirming that no other associated deficits, such as ASD, concurred. They attended regular schools and received special support either at school or in extracurricular sessions promoted by parents associations. Controls were chosen trying to ensure that the two groups were of similar socioeconomic conditions (medium/high).

The children were shown two quasi-identical pictures (the only difference was the reversal of the role of the participants in the event

\footnotetext{
${ }^{4}$ We were unable to put together a coherent group of language-matched controls for the experiments referred to in this paper. Therefore, we are not in a position to state whether or not the specificities observed in the case of the children with a diagnosis are the result of a shared developmental pattern typical of younger children in general. We thank an anonymous reviewer for reminding us of the need to declare this limitation of our study.
} 
depicted) and asked to select the one that matched the meaning of a sentence being read by the examiner. Images were always very similar, except that males and females systematically exchanged their roles in the event from one image to the other. In order to avoid interferences, agents were always located to the left and patients to the right in the image Figure (2). The task consisted of 20 items (plus 4 training items), 10 of which included subject questions and the other 10 included object questions. In each case, 5 questions contained a $\mathrm{WhP}$ of the type qué- $N$ 'which-N', and 5 a WhP of the type quién 'who'. Items were presented pseudo-randomly, ensuring that two items of the same type did not appear successively.
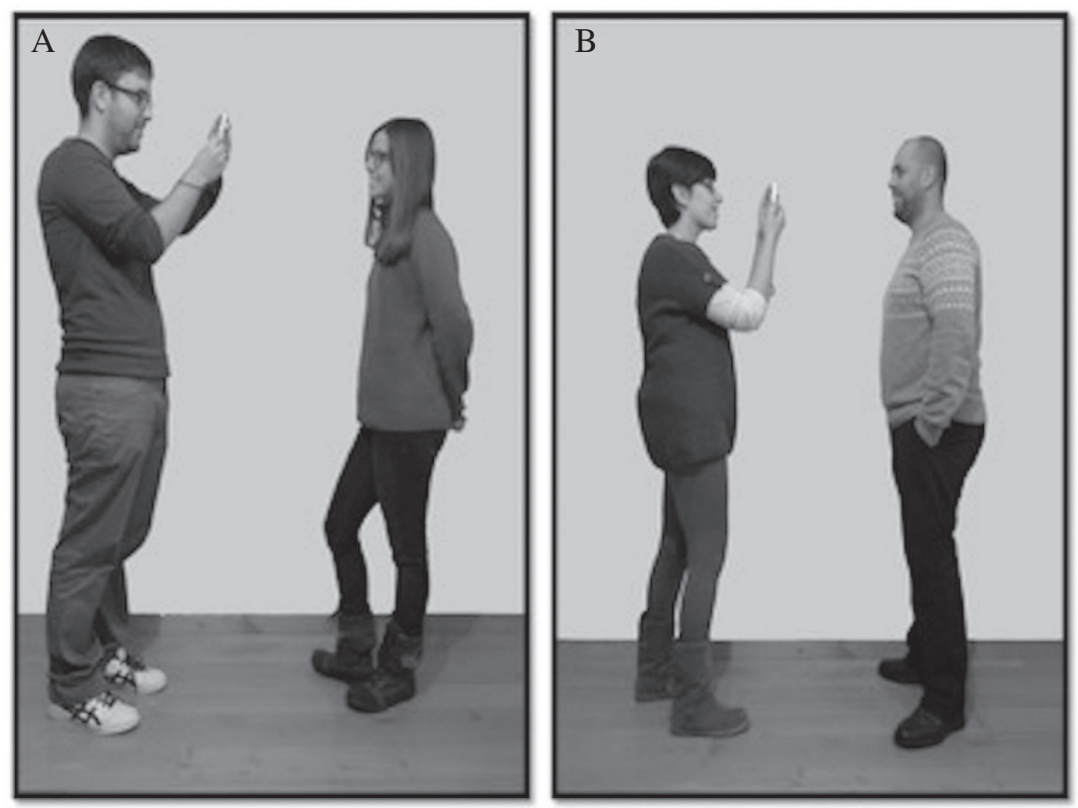

Figure 2. ¿A qué chico está fotografiando la chica? (to which boy is taking-a-picture the girl; Which boy is the girl taking a picture of?). Target: B.

Table 2 synthesizes the results, which clearly reflect (a.) an asymmetry between children with and without SLI, (b.) an asymmetry between object WhP and subject WhP interrogatives, and (c.) an asymmetry between $\mathrm{Wh}+\mathrm{NP}$ type and Wh type of WhP: $:^{5}$

${ }^{5}$ As aptly observed by an anonymous reviewer, there exists a risk of chance performance in this kind of experiment. However, as the same reviewer also points out, it is clear from the results that this is not a problem, at least not for subject Wh-phrases. In the case of object Wh-phrases, chance performance may show that the child does not master the construction. 
Table 2. Results of the test of comprehension of interrogative sentences. Percentage represents percent errors for the whole data set

\begin{tabular}{lcc}
\hline & SLI Group & Control Group \\
\hline Subject WhP & & \\
Who & $6.4 \%$ & $0.9 \%$ \\
Which_N & $8.2 \%$ & $0.0 \%$ \\
Object WhP & & \\
Who & $34.5 \%$ & $1.8 \%$ \\
Which_N & $60.9 \%$ & $8.2 \%$ \\
\hline
\end{tabular}

Observations: In the case of object wh-questions, a statistical meaningful difference is observed in the number of errors in comprehension, relatively to subject wh-questions $(z=-4.211 ; p=.000)$. In the case of subject wh-questions, no statistically meaningful differences are observed in the number of errors in comprehension sensitive to the kind of operator $(z=-.921 ; p=.357)$; in the case of object wh-questions, such difference contrarily exists $(z=-2.905 ; p=.004)$.

\subsubsection{Experiment 1: Analysis and discussion}

Observations similar to the ones in Table 1 have been independently documented and interpreted on different theoretical grounds before (cf. van der Lely \& Battell 2003, for the case of subject/object reversal; Friedmann \& Novogrodsky 2011, for the case of Wh-phrase weight). ${ }^{6}$ To our knowledge, no one has to date offered a unified account that relates them to problems with linearization.

The sentences that our population of children - (1) - found the least problematic were the ones in which the object and the subject were transferred to Ext in different phases, meaning that the children did not have to solve a linearization problem between these constituents. In these sentences, the subject WhP I-merges first to T (Spec, TP), just like other canonical DP subjects, and then to C (Spec, CP), like other scope-taking operators; in turn, the object DP remain $v \mathrm{P}$ internal, maybe in a Spec, $v \mathrm{P}$ position, as is argued to be the case of specific DP objects in general (Torrego 1998). Consequently, the following schematic analysis can be used for this type of sentences, where the scissors represent the derivational stages at which it is supposed that the material below is sent to Ext:

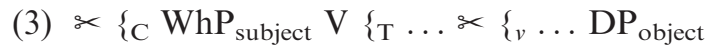

In contrast, in the sentences that these children - (2) - found most problematic, it was the WhP object that was attracted by the Extended Projection Principle feature (EPP) of C, thus ending up at the same phase

\footnotetext{
${ }^{6}$ More specifically, van der Lely \& Battel (2003) defend that children with SLI have problems with theta-role assignment in sentences that depart from canonical word order e.g. interrogatives with a fronted object WhP; Friedmann \& Novogrodsky (2011) claim that children have problems with the movement of constituents across constituents of the same type - e.g. a Wh+NP across a D+NP.
} 
level as the subject DP - as schematized in (4); as a result, a linearization problem has to be solved between these constituents:

(4) $\&$ \{ $\left\{\mathrm{WhP}_{\text {object }} \mathrm{V}\left\{\left\{_{\mathrm{T}} \mathrm{DP}_{\text {subject }} \ldots\right.\right.\right.$

This line of analysis may also be applied to explain the contrast between types of $\mathrm{WhP}$ objects, i.e. the fact that comprehension errors increase in the case of the Wh+NP type, in comparison to the bare Wh type. Note that in the former case - $(2 b)$, a further linearization problem must be solved between the Wh-word and the NP that it pied-pipes - see (5), and that the solution must be attained at the same phase level as the linearization of the complete object WhP and the subject DP. This is represented in (5):

(5) $\&<\left\{\mathrm{C}\left\{\mathrm{Wh}_{\mathrm{Wh}} \mathrm{Wh} \mathrm{NP}\right\}\right\}_{\text {object }} \mathrm{V}\left\{\mathrm{T}\right.$ DP $\mathrm{P}_{\text {subject }} \ldots$

The same problem does not arise in the case of (2a) - see (6), and consequently no extra problem is added in this case to the challenge of linearizing the object and the subject at the same phase level:

(6) $\&<\left\{\mathrm{C}\left\{\mathrm{Wh}_{\mathrm{Wh}} \mathrm{Wh}\right\}_{\text {object }} \mathrm{V}\{\mathrm{T} \mathrm{DP}\right.$ subject $\ldots$

As we will presently show, these conclusions are reinforced by observations made in production tasks with wh-questions.

\subsection{Linearization as a barrier for production}

The phenomena described and interpreted in the previous section raise the following prediction: If children with SLI show difficulties in deciphering linear order from hierarchical structure (and vice versa), they would be expected to show a tendency to distribute in different phases constituents that should, in normal conditions, appear in the same phase. Certain observations in tests aimed at examining these children's abilities in the production of wh-questions appear to bear out the prediction.

\subsubsection{Experiment 2: Participants, materials and results}

We tested 12 Spanish-speaking children with SLI (4 girls, 8 boys), ranging from 10;3 to $15 ; 0$ (M: 12;7), and 12 Spanish-speaking children with typical development (matched for gender and age). Children under 10 years of age did not the tests and were consequently excluded from this experiment. The sociological and psychological condition of the children were the same as in the experiment described in the previous section.

Children were asked to participate in an elicitation task based on an image of a girl and her mother, the latter clearly asking the former a question regarding a particular situation (e.g. a man introducing two pieces of bread into an oven). Children could see the girl's answer (e.g. en 
el horno 'in the oven') as well as the verb on which the mother's question, which they have to construct, should be based (e.g. cocinar 'to cook'), Figure 3 (for similar tests, cf. Metz et al. 2010, van der Lely et al. 2011). The task consisted of 20 items per child.

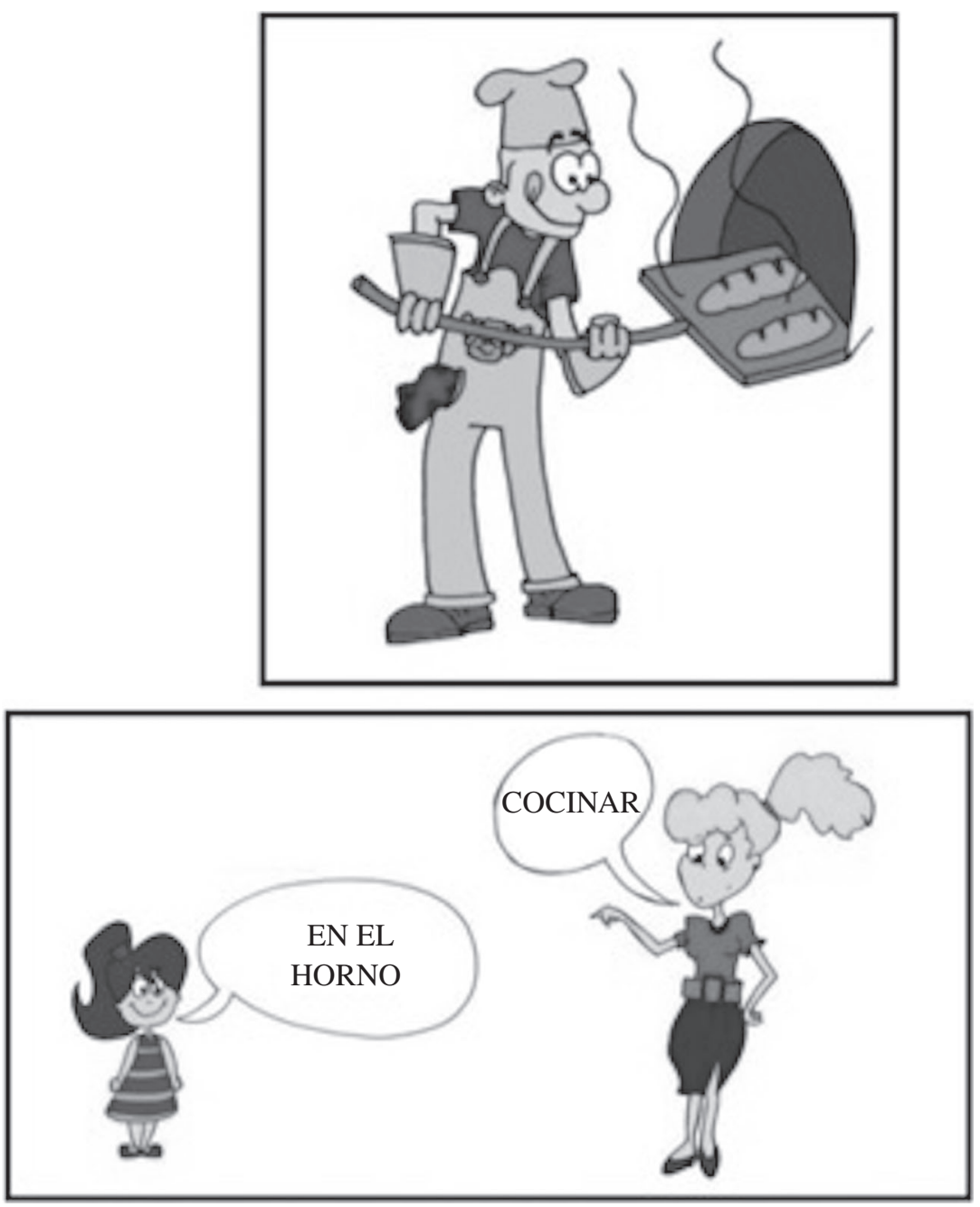

¿DÓNDE COCINÓ EL SEÑOR EL PAN?

Figure 3. Lower image: - Cocinar 'to cook'; - En el horno 'in the oven'. Expected target: ¿Dónde cocinó el señor el pan?; where cooked the man the bread; 'Where did the man cook the bread?'

Two particularly recurrent kinds of error were observed, illustrated in (7) and (8) below respectively. The first kind consisted of an atypical 


\section{Guillermo Lorenzo \& Elena Vares}

word order in which the subject DP preceded the WhP - subject + WhP, in Table 3. The second kind showed an atypical connection between a fronted WhP and a related constituent left in situ - Split WhP, in Table $3:^{7}$

(7) ¿El chico qué tiene?

The boy what has

(target: ¿Qué tiene el chico? 'What does the boy have?')

(8) ¿Qué encontró el niño un coche de color azul?

What find-past the boy a car of color blue

lit. 'What did the boy find a blue colored car?'

(target: ¿Dónde encontró el niño el cochecito? 'Where did the boy find the toy car?')

17 out of the total of 26 registered errors belonged to type (7), ${ }^{8}$ and 9 to type (8). Together, they accounted for $26.5 \%$ of the total errors in the children's production of wh-questions. The remaining errors were a heterogeneous collection of pragmatically deviant productions, such as interrogatives with unexpected wh-words or inappropriate declarative sentences. Grammatical errors were negligible in the controls. The results are offered in Table 3:

Table 3. Results of the test conducted to evaluate the production of interrogative sentences

\begin{tabular}{lcl}
\hline & SLI Group & Control Group \\
\hline Total & 26 & 1 \\
Subject + WhP & 17 & 1 \\
Split WhP & 9 & 0
\end{tabular}

Observations: The table quantifies the number of errors for the whole data set. The contrast between the number of errors in the Control group and in the SLI group is meaningful $(z=-4.322 ; p=.000)$.

\subsubsection{Experiment 2: Analysis and discussion}

As for sentences of type (7) - subject $+\mathrm{WhP}$, we interpret that the WhP corresponding to an (object) internal argument (or sometimes to

\footnotetext{
${ }^{7}$ This same construction has been attested in younger children with typical development in some languages (Gavruseva \& Thornton 2001, van der Lely \& Battel 2003). We have been unable to document close correlates of this kind of wh-split in Child Spanish. Solá \& Gavarró (2006), who document it in Catalan, claim that the case of Spanish is predicted by properties of the adult case system.

${ }^{8}$ An important note of clarification is that this construction cannot be identified with a common Spanish interrogative construction in which one constituent appears left dislocated and thus preceding the WhP. In this construction, intonation raises at the end of the dislocated element: El chico $(\uparrow)$ ¿qué tiene? (the boy $\uparrow$ what has). No such intonation mark is observed in the SLI construction under investigation.
} 
a verbal adjunct, as in La niña cómo salta; the girl how jumps; 'How does the girl jump?'), remains in a $v \mathrm{P}$ internal position as a strategy for being spelt out as soon as possible and thus avoiding entering the next phase stage. In this way, the (subject) external argument and the (wh) internal one can be materialized at different phases without creating the kinds of difficulties that we identified in the previous sections as regards comprehension. The relevant alleviating structure is specified in (9):

(9) $\&\left\{\mathrm{C}_{[+ \text {wh, }-\mathrm{EPP}]} \mathrm{DP}_{\text {subject }} \mathrm{T}_{[+\mathrm{EPP}]} \ldots \propto\left\{{ }_{v} \mathrm{WhP} v_{[+\mathrm{EPP}]} \cdots\right.\right.$

According to this interpretation, in order for such an effect to be achieved, the +EPP feature that customarily instigates the displacement of the WhP to C, is attached to $v$ instead. A second +EPP feature is in turn attached to $\mathrm{T}$ as usual, which attracts the external DP argument. Given this state of affairs, the sentence obtains illocutive (interrogative) force via the feature specification of $\mathrm{C}_{[+ \text {wh, }}$-EPP] without the standard accompanying fronting of the WhP. ${ }^{9}$ As predicted, the linearization conflict is alleviated.

If interpreted as suggested, examples like (7) become theoretically relevant, for they defy Chomsky's (2004:123) claim that "no clear case of stranding in Spec- $v$ is known", which is however what happens in (7) according to our analysis - i.e. (9). Note that in cases like this, the object WhP should block the subject's way to Spec-T from its starting position at an inner Spec- $v$ layer. According to Chomsky, no conflict arises in normal circumstances, since when the object WhP I-Merge with $\mathrm{C}$, the remaining copy does not have the same disturbing effect. Our examples appear to illustrate that speakers with SLI predominantly use configurations that alleviate their difficulties with linearization, despite this being in conflict with normal economy standards, thereby adding an exceptional pattern to the catalogue of attested linguistic typologies - namely, an exceptional Spec- $v$ stranding construction of sorts.

As for sentences of type (8) - i.e. split WhP, they entail, to start with, a pragmatic anomaly without parallels in the elicited productions of the controls: Children with SLI appear to be firmly focusing their attention on a salient element of the situation (e.g. a blue car in the picture), and instead of creating something similar to the expected target, they try, instead, to construct a question that includes that element. What results is also semantically deviant, for it contain a restrictor of sorts, one that exhaustively restricts the range of entities of the relevant kind to which

\footnotetext{
${ }^{9}$ We assume that no V-to-T overt head movement occurs, so what surfaces is a verb-final wording. Our suggestion regarding this is that the ultimate driving force of V-movement in regular cases is the need to reach $\mathrm{C}$ for the licensing of $+\mathrm{EPP}$, which is absent in the cases under investigation.
} 
the interrogative operator applies: In the case of (8) above, something like $<$ what $(\mathrm{x}) /$ a blue colored car $(\mathrm{x})>$. We interpret that children first merge $\mathrm{V}$ and a constituent expressing this restricted quantification, and then they I-Merge the operator component - i.e. $<$ what $(\mathrm{x})>-$ to $\mathrm{C}$, leaving the restrictor behind - i.e. $<$ what $(x) /$ a blue colored car $(x)>.^{10}$ What surfaces is a sentence like (8).

According to our interpretation, I-merging the whole quantifier to $\mathrm{C}$ would entail a strong linearization challenge. Note that children would confront the task of solving the linear ordering within the complex WhP at the same phase in which they would also have to resolve the relative linear order of the object WhP and the subject DP. In contrast, by leaving behind part of the former, the constituents end up at different phases, as in (10), ${ }^{11}$ alleviating linearization:

$$
) \&\left\{\mathrm{C} W(\mathrm{x}) \mathrm{C}_{[+w h,}+\mathrm{EPP}\right] \mathrm{DP} \mathrm{T}_{[+\mathrm{EPP}]} \ldots \&\left\{{ }_{v} \mathrm{Wh}(\mathrm{x}) \mathrm{R}(\mathrm{x}) \ldots\right.
$$

Against this analysis, the objection may be raised that if the original object WhP has a DP status, and if DPs are candidates for phasehood (Svenonius 2004), then no such an alleviating strategy appears to be required. Instead, it would suffice to extract the Wh word from the object Wh/DP and to I-merge it to $v$. Once there, it could remain stranded, along the lines of (9). Were this the case, Wh would be unproblematically spelt out at the lower, $v$ phase level, independently of the rest of the DP, itself a phase, as illustrated in (11):

$$
\begin{aligned}
& \&\left\{\left\{_ { C } C _ { [ + w h , - E P P ] } D T _ { [ + E P P } \ldots \& \left\{{ }_{v} \mathrm{Wh}(\mathrm{x}) v_{[+\mathrm{EPP}]} \cdots\right.\right.\right. \\
& \&\{\mathrm{DWh}(\mathrm{x}) \mathrm{R}(\mathrm{x}) \ldots
\end{aligned}
$$

However, it is far from clear that WhPs have a DP status. From a semantic point of view, WhPs are obviously closer to QPs (e.g. algunos coches 'some cars') than to DPs proper (e.g. los coches 'the cars'), since the latter are associated to semantic values like 'definiteness' or 'specificity,' alien or less accessible to the former (Leonetti 2012). Syntactically, it is a well-known fact of Spanish that DPs, but not QPs,

\footnotetext{
${ }^{10} \mathrm{Here}$, and in all the following examples, we use the copy theory of movement (Chomsky 1995), according to which repetitions of a single unit may be inserted at different locations and then deleted, except one (usually, the highest one). Deleted copies are represented by crossing them out.

${ }^{11}$ Among the productions of children with SLI we found subjectless sentences - ¿Dónde está subiendo en el tejado? (where-is-climbing-on-the-roof, 'Where is he climbing on the roof?'), but we do not believe that these challenge our conclusion. Note that in this kind of sentence, a whole tripartite generalized quantification structure (Operator / Restrictor / Scope) still needs to be linearized - where (x) / a roof (x) / is-he-climbing-on (x), and that the suggested alleviating effect is obtained by splitting it into two independently externalized components $-\&<\{$ where $(\mathrm{x}) /$ is-he-climbing-on $(\mathrm{x}) / \&<$ \{a roof $(\mathrm{x})$, which, interestingly enough, does not correspond to standard expectations - i.e. \& \{Operator / Restrictor \& \{Scope. On the relation between generalized quantification and phasehood, see for example Carnie \& Barss (2006), as well as the comments on Citko (2014:200-203).
} 
are barriers for extraction - see, among others, Ticio (2005), as attested in the following contrast:
a. * ¿Sobre qué has leído [D el nuevo libro søbre qué? about what have-you read the new book 'Concerning what have you read the new book?'
b. ¿Sobre qué has leído [Q algún nuevo libro sobre qué? about what have-you read some new book 'Concerning what have you read any new book?'

Wh-phrases align closer to QPs than to DPs in this respect also, as shown in examples with multiple Wh-phrases like (13):
¿Sobre qué has leído $[\mathrm{wh}=\mathrm{Q}$ about what have- you qué nuevo libro
what new book 'Concerning what have you read which new book?'

All this entails that the operator component of the complex Wh-phrases, in contrast to examples of type (7), cannot remain within the $v \mathrm{P}$. In a configuration like the one for (7) - i.e. (9), given that the object WhP as a whole has a non-phase character, the operator (in Spec, $v \mathrm{P}$ ) and the restrictor (within the object of the same projection) would be sent together to Ext. In order to avoid this, the Wh-operator is forced to move to the next phase, thus landing at the CP level. ${ }^{12}$

Before closing this section, let us point out that if our interpretation of the phenomena thus far reviewed is on the right track, a relevant theoretical consequence follows regarding the phases/spell-out dynamics. There is no consensus in the literature as to whether the unit that is cyclically delivered to Ext for spell-out corresponds to the whole phase, or only to its domain - i.e. everything except the phase's edge (Spec) and head $(\mathrm{H})$, which remain accessible to further computations (Boeckx \& Grohmann 2007:215, Citko 2014:37). In other words, it is not completely clear whether the distinction imposed by the Phase Impenetrability Condition (PIC; Chomsky 2000) - according to which the domain of a phase is not accessible to the Computational System for further operations - is the reflex of an independent constraint, or rather is derivative of the material that is actually sent to Ext. Note that, on conceptual grounds, the latter alternative appears to be preferable, for it immediately explains the locality constrain without adding an extra one: The phase's domain is impenetrable because it has already been delivered to Externalization. Yet, this alternative appears to lead to an erroneous

\footnotetext{
${ }^{12}$ Corver et al. (2012), drawing from Southwood (2007), offer some (minor) cases of mislinearization in the productions of Afrikaans-speaking children with SLI, in which adjacent elements appear in reverse order to that which would be expected-e.g. OV instead or VO, OP instead of PO, etc. These kinds of examples can be subsumed under our general hypothesis by interpreting them as sporadic errors in the application of the LCA algorithm itself.
} 
prediction for cases like (7) above - interpreted as (9), as well as for many other examples in our database, in which the conflicting elements would end up being delivered to Ext simultaneously. Note that if WhP remains at the edge (Spec) of $v \mathrm{P}$, and the edge of $v \mathrm{P}$ is not part of the lower phase, then WhP would end up being problematically linearized relative to the subject DP at the upper phase. It is thus our opinion that observations like the ones offered in this and the previous section point to the alternative that Ext waits until the $v \mathrm{P}$ is accomplished, so it is then this whole unit, comprising both the edge and the head, which is sent for spell-out altogether. ${ }^{13}$

\section{Conclusions}

According to Chomsky (1980), establishing the psychological reality of the theoretical constructs of linguistic theory is not an issue which is independent from that of establishing the constructs themselves. Linguistic constructs are real in as much as they generate predictions that do not run against the linguistic record provided by the speakers of a given community/population. There is not a plane of linguistic reality and another, independent plane of psychological reality, which the former must somehow match in order to be sanctioned as real. There is but one plane of reality, which comprises the mental one - including language, in as much as it has a place within our metaphysical assumptions. Theoretically speaking, the constructs of linguistics and the constructs of psychology constrain each other: What one concludes from a linguistic point of view must (ideally) fit what is independently concluded from a psychological point of view, and what one concludes from the psychological perspective must (ideally) fit, if relevant, what is independently known from the linguistic perspective. There is a trade-off between the perspectives, not an asymmetrical relation. The study of linguistic impairments lies somehow in between the concerns of linguistics and psychology.

Our particular approach to SLI has been conducted with the conceptual and experimental tools of linguistics. Taking advantage of some recent insights of the Minimalist Program, we have been able to offer a coherent, more unified explanation to phenomena that have previously been dealt with separately. In short, we have derived them from a single explanatory source - namely, the phase-based theory of linearization:

\footnotetext{
${ }^{13}$ In this we follow, for example, Fox \& Pesetsky's (2005) position, according to which the PIC may be thought of as derivative of an (extra) phonological constraint: Namely, one that imposes that I-Merge must be order-preserving across successive phase levels. Note that edge-to-edge I-Merge is uniformly head-final, while domain-to-edge is not - it starts headinitial. As a consequence, I-Merged constituents must escape phase-domains in a successive cyclic manner in order to keep a uniform record of the ordering information added each time Spell-out applies.
} 
(i) why object Wh-questions and subject $\mathrm{Wh}+\mathrm{NP}$-questions are more challenging to comprehend for children with SLI, compared to subject Wh-questions; and

(ii) why complex Wh-phrases split in the productions of the same populations.

Regarding (i), previous approaches have traditionally relied on difficulties regarding theta-roles in sentences with non-canonical word order, like wh-questions, to explain the object/subject asymmetry (Friedmann \& Novogrodsky 2007, 2011). However, theta-theory is of no use in explaining the Wh vs. Wh+NP contrast. We do believe that children with SLI have difficulties related with theta-role interpretation. However, we have argued elsewhere that such difficulties cannot be explained as being due to limitations in computing linear word order, as theta-roles are not assigned on a linear order basis to begin with. In all likelihood, whatever problems children with SLI have with theta roles, they are to be related to the weakness of their capacity to reconstruct from the linear stimulus the correct hierarchical relations (first merge $>$ theme, second merge > agent, and so on; Chomsky 2008), on which theta roles are as a matter of fact based (Lorenzo \& Vares 2017). We thus conclude that our externalization-centered model predicts problems with theta roles, of the kinds stressed by Friedmann and Novogrodsky, but that it also explains other kinds of problems, like the Wh vs. Wh+NP contrast, in a unitary way, which their model does not.

As for (ii), van der Lelly \& Battel (2003) argue that the whole mechanism that underlies movement operations is spared in the grammars of children with SLI. Nevertheless, an economy principle, which refrains from using that mechanism except when forced by some other principle, is impaired, so children behave randomly in this area of grammar. In short, they claim that the affectation may reside in the requirements of the Wh-word. When this is the case, children occasionally construct sentences with an XP that surfaces at a $v \mathrm{P}$ internal position and they E-merge the Wh-word directly to $\mathrm{C}$ - the type illustrated in our (8). Note that our own hypothesis is compatible with van der Lelly and Battel's suggestion that core aspects of grammar are spared in the case of children with SLI, as we claim that in the cases under investigation it is the Ext component alone that is impaired. However, we believe our hypothesis to be stronger than theirs, as the subject/object asymmetry, which we explain, is, in contrast, not predicted by their model.

From a broader theoretical perspective, our conclusions seem to offer support to some central claims of current Minimalist theorizing: namely, the autonomy of an Externalization module (Ext), comprising a natural kind of mechanisms ranging from Linearization to Phonetics, the centrality of a flattening mechanism based on command for transferring hierarchical to linear order (LCA), and - more tentatively - 
the integrity of phases as units for spell-out. Moreover, these conclusions also appear to offer support to some claims independently made from a psychological and even from a neurobiological perspective. From the latter point of view, the contention has been made, for example, that a particular tract of fibers exists that connects frontal and dorsal areas related to Ext, superior to the classical dorsal circuit also known as Arcuate fasciculus that putatively relates with more central computations (Friederici 2011). From the former perspective, for example, disruptions of a phonological loop of operative or working memory have traditionally been associated to SLI phenomena, which is plausibly segregated from other putative loops involved in more central computations (Gathercole \& Baddeley 1990). Besides, these results are congenial with the conclusion of those who claim that FOXP2, the disruptions of which underlie the best-known cases of SLI, is a transcription factor that specifically relates to Ext, not to Narrow Syntax (Berwick \& Chomsky 2011, Berwick \& Chomsky 2016). In view to such considerations, we believe that this contribution to the understanding of SLI may qualify as a realistic one, a category certainly more modest than deeming it real, but surely closer to the ambitions of science.

\section{References}

Berwick, R. C. \& Сhomsky, N. 2011. The Biolinguistic Program: The current state of its development. The biolinguistic enterprise. New perspectives on the evolution and nature of the human language faculty. eds. A.M. di Sciullo \& C. Boeckx, 19-41. Oxford: Oxford University Press.

Berwick, R. C. \& Chomsky, N. 2016. Why only us. Language and evolution. Cambridge, MA: MIT Press.

Bishop, D. V. M. 1997. Uncommon understanding: Development and disorders of language comprehension in children. Hove \& New York: Psychology Press.

Bishop, D. V. M. 2014. Ten issues about terminology for children with unexplained language problems. International Journal of Language and Communication Disorders 49:381-415.

Boeckx, C. 2014. Elementary syntactic structures. Prospects for a feature-free grammar. Cambridge: Cambridge University Press.

Boeckx, C. \& Grohmann, K. K. 2007. Remark: Putting Phases in Perspective. Syntax 10:204-222.

CARnie, A. \& Barss, A. 2006. Phases and nominal interpretation. Research in Language 4:127-132.

Сномsкy, N. 1965. Aspects of the theory of syntax. Cambridge, MA: MIT Press.

Chomsky, N. 1980. Rules and representations. New York, NY: Columbia University Press.

Сномsкy, N. 1995. The minimalist program. Cambridge, MA: MIT Press.

Снomsky, N. 2000. Minimalist inquiries: The framework. Step by step. ed. R. Martin, D. Michaels \& J. Uriagereka, 69-126. Cambridge, MA: MIT Press.

Сномsку, N. 2004. Beyond explanatory adequacy. The cartography of syntactic structures. Vol.3. Structures and beyond. ed. A. Belletti, 104-131. Oxford: Oxford University Press. 
Chomsкy, N. 2008. On phases. Foundational issues in linguistics: Essays in honor of Jean-Roger Vergnaud. ed. R. Freidin, C. P. Otero \& M. L. Zubizarreta, 133166. Cambridge, MA: MIT Press.

Chomsky, N. 2013. Problems of projection. Lingua 130:33-49.

Chomsky, N. 2016. What kind of creatures are we? New York, NY: Columbia University Press.

Ciтко, B. 2014. Phase theory. An introduction. Cambridge: Cambridge University Press.

Corver, N., Southwood, F. \& van Hout, R. 2012. Specific Language Impairment as a syntax-phonology (PF) interface problem: Evidence from Afrikaans. Stellenbosch Papers in Linguistics 41:71-89.

de Villiers, P., de Villiers, J., Roeper, T. \& Seymour, H. N. 2001. Assessing what every 5-year-old should know. Transcription of a Session held at the 2001 ASHA Annual Convention, New Orleans, LA. < https://www.umass.edu/aae/ ASHA_5_yr_old_2001.doc >

Epstein, S. D., Groat, E. M, Kawashima, R. \& Kitahara, H. 1998. A derivational approach to syntactic relations. Oxford: Oxford University Press.

Fodor, J. A. 1975. The language of thought. Cambridge, MA: Harvard University Press.

Fodor, J. A. 1983. The modularity of mind. Cambridge, MA: MIT Press.

Fodor, J. A. 2008. LOT 2: The language of thought revisited. Oxford: Oxford University Press.

Fox, D. \& Pesetsky, D. 2005. Cyclic linearization of syntactic structure. Theoretical Linguistics 31:1-45.

Friedmann, N. \& Novogrodsky, R. 2007. Is the movement deficit in syntactic SLI related to traces or to thematic role transfer? Brain and Language 101:50-63.

Friedmann, N. \& Novogrodsky, R. 2011. Which questions are most difficult to understand? The comprehension of Wh questions in three subtypes pf SLI. Lingua 121:367-382.

Friederici, A. D. 2011. The brain basis of language processing: From structure to function. Physiological Reviews 91:1357-1392.

Gathercole, S. E. \& Baddeley, A. D. 1990. Phonological memory deficits in language disordered children: Is there a causal connection? Journal of Memory and Language 29:336-360.

GAvarró, A. 2012. Third person clitic production and omission in Romance SLI. Pronouns and clitics in early language. ed. P. Guijarro-Fuentes \& P. Larrañaga, 79-104. Berlin/Nova York: De Gruyter/Mouton.

GopNIK, M. 1990. Feature-blind grammar and dysphasia. Nature 344:715.

Gopnik, M. \& Crago, M. B. 1991. Familial aggregation of a developmental language disorder. Cognition 39:1-50.

Grinstead, J., Lintz, P., Vega-Mendoza, M., De La Mora, J., Cantú-Sánchez, M. \& Flores-Avalos, B. 2014. Evidence of optional infinitive verbs in the spontaneous speech of Spanish-speaking children with SLI. Lingua 140:52-66.

HÅKANSSON, G. 1998. Language impairment and the realization of finiteness. Boston University Conference on Language Development Proceedings 22:314-324.

Hamann, C. 2006. Speculations about early syntax: The production of whquestions by normally developing French children and children with SLI. Catalan Journal of Linguistics 5:143-189.

Hansson, K. \& Nettelbladt, U. 2006. Wh-questions in Swedish children with SLI. International Journal of Speech-Language Pathology 8:376-383.

Hsu, H. J. \& Bishop, D. V. M. 2014. Sequence-specific procedural learning deficits in children with specific language impairment. Developmental Science $17: 352-365$. 
Jakubovitz, C. 2011. Measuring derivational complexity: New evidence from typically developing and SLI learners of L1 French. Lingua 121:339-351.

KAYNE, R. 1994. The antisymmetry of syntax. Cambridge, MA: MIT Press.

LEONARD, L. B. 1995. Functional categories in the grammars of children with specific language impairment. Journal of Speech, Language, and Hearing Research 38:1270-1283.

Leonard, L. B. 2014. Children with Specific Language Impairment. Cambridge, MA: MIT Press.

LeOnetTI, M. 2012. Indefiniteness and specificity. The Handbook of Hispanic Linguistics. eds. J. I. Hualde, A. Olarrea \& E. O'Rourke, 185-305. Chichester: Wiley and Sons.

Lorenzo, G. \& Vares, E. 2017. The Externalization component as a locus of specific impairments. Biolinguistics 11:1-19.

Metz, M., van Hout, A. \& van der Lely, H. 2010. Understanding who and which questions in five to nine-years-old Dutch children: The role of number. Groninger Arbeiten zur germanistischen Linguistik 51:27-41.

Rapin, I. \& Allen, D. 1983. Developmental language disorders: Nosologic considerations. Neuropsychology of language, reading and spelling. ed. U. Kirk, 155-184. New York, NY: Academic Press.

Rapin, I. \& Allen, D. 1987. Developmental dysphasia and autism in preschool children: Characteristics and subtypes. Proceedings of the First Symposium on Specific Speech and Language Disorders in Children, 20-35. London: AFASIC.

Reilly, S., Bishop, D. V. M. \& Tomblin, B. 2014. Terminological debate over language impairment in children: Forward movement and sticking points. International Journal of Language and Communication Disorders 49:452-462.

Rice, M. L. \& Wexler, K. 1996a. A phenotype of Specific Language Impairment: Extended Optional infinitives. Towards a genetics of language. ed. M. L. Rice, 215-237. Mahwah, NJ: Lawrence Erlbaum Associates.

Rice, M. L. \& Wexler, K. 1996b. Toward tense as a clinical marker of Specific Language Impairment in English-speaking children. Journal of Speech, Language and Hearing Research 39, 1239-1257.

Rice, M. L., Wexler, K. \& Cleave, P. L. 1995. Specific Language Impairment as a period of extended optional infinitive. Journal of Speech, Language and Hearing Research 38:850-863.

Southwood, F. 2007. Specific Language Impairment. Providing a minimalist account for problems with grammatical features and word order. Utrecht: LOT.

Stavrakaki, S. 2006. Developmental perspectives on Specific Language Impairment: Evidence from the production of wh-questions by Greek SLI children over time. Advances in Speech-Language Pathology 8:384-396.

Stavrakaki, S. ed. (2015). Specific Language Impairment. Current trends in research. Amsterdam: John Benjamins.

Svenonius, P. 2004. On the edge. Peripheries. Syntactic Edges and Their Effects. ed. D. Adger, C. de Cat \& G. Tsoulas, 261-287. Dordrecht: Kluwer.

Tesnière, L. 1959. Eléments de syntaxe structurale. Paris: Klincksieck.

Ticio, M. E. 2005. Locality and anti-locality in Spanish DPs. Syntax 8:229-286.

Torrego, E. 1998. The dependencies of objects. Cambridge, MA: MIT Press.

Tuller, L., Delage, H., Monjauze, C., Piller, A.-G. \& Barthez, M.-A. 2011. Clitic pronoun production as a measure of atypical language development in French. Lingua 121:423-441.

Ullman, M. T. \& Pierpont, E. I. 2005. Specific Language Impairment is not specific to language: The procedural deficit hypothesis. Cortex 41:399-433.

Uriagereka, J. 1999. Multiple Spell-Out. Working minimalism. eds. S. D. Epstein \& N. Hornstein, 251-282. Cambridge, MA: MIT Press. 
VAN DER Lely, H. K. 1998. SLI in children: Movement, economy, and deficits in the computational system. Language Acquisition 7:161-192.

VAN DER Lely, H. K. 2005. Domain-specific cognitive systems: Insight from Grammatical-SLI. Trends in Cognitive Sciences 9:53-59.

VAN DER Lely, H. K. \& BATTELl, J. 2003. Wh-movement in children with grammatical SLI: A test for the RDDR hypothesis. Language 79:153-181.

van Der Lely, H. K., Jones, M. \& Marshall, C. R. 2011. Who did Buzz see someone? Grammaticality judgment of wh-questions in typically developing children and children with Grammatical-SLI. Lingua 121:408-422.

Verhoeven, L. \& van Balkom, H. eds. 2004. Classification of developmental language disorders. Mahwah, NJ: Lawrence Erlbaum Associates.

WeXler, K. 1994. Optional infinitives, head movement and the economy of derivations. Verb movement. eds. D. Lightfoot \& N. Hornstein, 305-340. New York, NY: Cambridge University Press.

Zwart, J.-W. 2011. Structure and order: Asymmetric Merge. The Oxford handbook of linguistic minimalism. ed. C. Boeckx, 96-118. Oxford: Oxford University Press.

Received March 12, 2018

Guillermo Lorenzo

Accepted May 9, 2019

Universidad de Oviedo

Campus de Humanidades El Milán

C/Amparo Pedregal s/n

E-33011 Oviedo (Spain)

glorenzo@uniovi.es

Elena Vares

Escuelas Universitarias Gimbernat-Cantabria

Campus Torrelavega

C/ Aurelio García Cantalapiedra s/n

E-39316 Tanos-Torrelavega (Spain)

elena.vares@eug.es 